\title{
O conhecimento linguístico em livros introdutórios: uma reflexão sobre o modo de conceber a linguística ${ }^{1}$
}

\author{
Caroline M. Schneiders (UFSM) ${ }^{2}$
}

Resumo: No presente estudo, observaremos como a Linguística é definida nos anos de 1970, quando ela ainda passa por um processo de solidificação, e como ela está definida na atualidade, a partir dos anos 2000. Como objeto de reflexão, selecionamos livros introdutórios à Linguística: Introdução à lingüística, de Leonor Scliar Cabral, e Introdução à Linguística I e II, organizados por José Luiz Fiorin. A partir disso, interessa-nos compreender como se constitui e circula um discurso sobre a Linguística em condições e conjunturas diferentes.

Palavras-chave: Linguística; conhecimento; condições de produção.

\section{Considerações iniciais}

Interessa-nos, neste estudo, destacar uma reflexão que envolve a história do conhecimento linguístico que vem se desenvolvendo, sobretudo, a partir da institucionalização e disciplinarização da Linguística no contexto brasileiro. Nosso objetivo é observar como a Linguística é definida nos anos de 1970, quando ela ainda passa por um processo de solidificação, e como ela está definida na atualidade, a partir dos anos 2000.

Para tanto, possuímos como objeto de análise livros denominados de introdução à Linguística para compreender como essa discursividade, que tem por característica tratar de questões essenciais a respeito de uma temática, mas de um modo mais compreensível, concebe a Linguística em determinadas condições sócio-históricas e ideológicas. Entendemos que se torna relevante lançar um olhar sobre esses livros, pois visam à divulgação e, principalmente, à circulação do saber sobre as ideias linguísticas, tornando esse saber acessível a um público maior. Os livros selecionados são: Introdução à lingüística de Leonor Scliar Cabral, e Introdução à Linguística I e II, organizados por José Luiz Fiorin.

Esses livros são representativos para diferentes conjunturas e contextos. O primeiro refere-se ao contexto do Rio Grande do Sul,

$1 \mathrm{O}$ presente artigo trata-se de um recorte do estudo realizado junto à disciplina História do conhecimento linguístico, ministrada pela Prof. ${ }^{a}$ Dr. Amanda Eloina Scherer.

${ }^{2}$ Doutoranda em Letras do Programa de Pós-Graduação em Letras/UFSM e bolsista da Capes.

E-mail: carolletras2005@yahoo.com.br 
destacando-se devido à importância que Scliar Cabral teve para a instauração de "um discurso fundador do lugar de uma Lingǘstica voltada para o ensino do que propriamente teórica" (SCHERER, 2005, p. 21). Já o segundo livro, trata-se de um manual que se destaca, nos anos 2000, no âmbito nacional, tendo uma grande repercussão nos cursos de Letras, uma vez que se tornou leitura base tanto para os ingressantes nessa área de conhecimento quanto para alunos de pós-graduação.

Para o desenvolvimento desse trabalho, inscrevemo-nos na perspectiva da História das Ideias Linguísticas (HIL) vinculada à Análise do Discurso (AD) de orientação pecheutiana. Tendo em vista essa filiação, consideramos como essencial a noção de condições de produção, a fim de compreender como cada materialidade se constitui, atentando, em especial, ao modo como a história se inscreve na língua, produzindo efeitos de sentidos (cf. ORLANDI, 2004).

\section{Os livros introdutórios e a circulação do conhecimento}

Partimos da consideração que os livros introdutórios se configuram como um discurso sobre, em nosso caso, como um discurso sobre a Linguística ${ }^{3}$. Diante disso, a compreensão de como a Linguística se define nesses livros deve levar em conta a determinação histórica que constitui cada materialidade, para, desse modo, observar em que medida a temporalidade e a exterioridade se inscrevem no processo discursivo. A determinação histórica de cada materialidade relaciona-se às condições de produção, possibilitandonos entender quais saberes/dizeres estão em circulação em determinada conjuntura sócio-histórica e ideológica, bem como as filiações de sentidos que se estabelecem.

Tendo em vista o objeto de estudo que delimitamos, procuramos, a partir deste momento, propor algumas considerações que visam ao modo como a Linguística se apresenta na materialidade discursiva segundo certas condições, a fim de compreender também como se constitui e circula um discurso sobre a Linguística em conjunturas diferentes.

Primeiramente, destacaremos algumas observações a respeito do livro Introdução à lingüística de Leonor Scliar Cabral, cuja publicação é de 1973, sendo resultante da compilação de textos que foram publicados, nos anos de 1966 a 1967, no Jornal Diário de Notícias ${ }^{4}$. É relevante considerar esse dado,

\footnotetext{
${ }^{3}$ A distinção entre discurso de e discurso sobre pode ser observada em Orlandi (1990). Para a autora (Ibid., p. 37), o discurso sobre se trata de "uma das formas cruciais da institucionalização dos sentidos", sendo um "lugar importante para organizar as diferentes vozes (dos discursos de)".

${ }^{4}$ Um estudo mais apurado sobre esse livro pode ser observado na dissertação de Rosemary Candaten Xavier, intitulado Leonor Scliar Cabral: uma historicidade possível na produção do
} 
pois nos indica que a materialidade está vinculada a dois modos de circulação, e, por conseguinte, dois modos de divulgação.

Pela publicação do livro, podemos observar a que público o mesmo se destina, bem como seu objetivo, como nos mostra a breve apresentação junto à parte interna da capa do livro:

Destinado, fundamentalmente, aos estudantes dos cursos de Letras e Comunicação, este livro tem por objetivo iniciá-los gradativamente na ciência da linguagem articulada, começando por definir o objeto e métodos da linguística, dentro de uma perspectiva histórica, e situando-a no quadro das demais ciências (SCLIAR CABRAL, 1973, s/n).

Segundo Xavier (2004), essas formas de circulação dos estudos de Scliar Cabral contribuíram para divulgar a Linguística no sul, visto que se tratava de um "período em que poucos estudiosos sabiam ou falavam sobre esse domínio do conhecimento, pois a Lingüística estava começando a se constituir, a tomar corpo no Brasil” (p. 37-38).

Como sabemos, a Linguística foi institucionalizada como disciplina obrigatória nos cursos de Letras via decreto Federal no ano de 1962. Anterior a esse período, a Linguística não possuía um lugar reconhecido diante dos estudos da linguagem, sendo praticada e divulgada por um grupo restrito de estudiosos (cf. ALTMAN, 2004)5. É importante mencionar que nesse momento, devido à falta de formação especializada, quem se dedicava à Linguística nem sempre possuía uma formação na área, como, é o caso de Leonor Scliar Cabral, formada em Direito, que estava no último ano do curso de Letras quando da publicação de seus artigos no Jornal Diário de Notícias. Desse modo, "o sujeito com formação em outras áreas, mas dedicado aos estudos lingüísticos, era autorizado a assumir a posição de sujeito lingüista" (XAVIER, 2004, p. 52).

Considerando essas questões, observaremos como a Linguística está definida e/ou representada no livro de Scliar Cabral, Introdução à lingüística, pontuando questões que nos permitem entender que recorte se tem sobre o objeto da Linguística nos livros de divulgação selecionados. Nossas observações, no livro de Scliar Cabral, serão, sobretudo, a respeito do capítulo 1: O que é Lingüística, mencionando também alguns pontos do capítulo 2, Divisões da Lingüistica.

saber sobre a lingüística na mídia impressa do RS, 2004. Estudo realizado junto ao PPGL/UFSM sob a orientação da Prof. ${ }^{a}$ Dr. Amanda E. Scherer.

${ }^{5}$ A Linguística era introduzida junto a outras disciplinas dos cursos de Letras, ou circulava em obras desse período, como as de Mattoso Câmara, e em revistas como a Revista Brasileira de Filologia. 
Podemos dizer que o primeiro capítulo, dedicado a especificar o que é a Linguística, aponta para um discurso que se filia à Linguística europeia e americana. Essa filiação está explicitada pelo seguinte recorte: "A lingüística

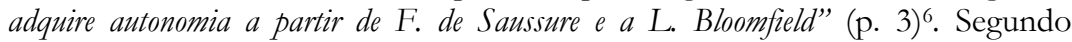
Pêcheux (1999, p. 10), "o pensamento de Saussure se estende até o estruturalismo distribucional de Bloomfield", ou seja, há um vínculo entre esses estudiosos, embora a vertente americana passe a desenvolver estudos com uma abordagem diferenciada. Diante disso, torna-se necessário observar como essas duas filiações se relacionam com os dois pontos principais desse capítulo: Objeto da lingüistica, e $O$ método.

No que se refere ao objeto, destaca-se que anterior a esses dois estudiosos não havia sido precisado o objeto da Linguística, ou seja, marca uma distinção entre os estudos que se faziam antes da definição do objeto da Linguística e os que passaram a ser realizados: "O objeto da Linguística não bavia sido precisado até então, dai decorrendo a inexistência de um método próprio" (p. 3). Nessa parte do capítulo, verifica-se, especialmente, a ênfase nas considerações de Saussure, como quem definiu, no início do século XX, 'com maior clareza, o objeto da lingüistica', trazendo sua célebre dicotomia língua (langue) versus discurso (parole) $)^{7}$.

Após situar quando e quem definiu o objeto da Linguística, destaca-se a segunda metade do século XX com os estudos da Gramática GerativoTransformacional (GGT), cujo principal representante é Chomsky, que segue na linha de estudos propostos por Bloomfield. Essa abordagem americana está inserida a fim de marcar a possibilidade de outro olhar sobre o objeto da Linguística, considerando que essa escola "determinou uma verdadeira reformulação quanto ao objeto da lingïistica" (p. 4-5), mas procurou aproveitar alguns aspectos que Saussure propôs, mesmo divergindo da perspectiva saussuriana. A ênfase em Chomsky pode ser decorrente do fato de que é nos anos 60/70 que se inicia a sua recepção no Brasil, ou seja, podemos observar que há uma determinação histórica na constituição discursiva.

$\mathrm{Na}$ parte sobre o método, há novamente a presença das duas filiações já mencionadas para apontar como cada viés concebe o método, segundo o entendimento que se tem sobre o objeto da Linguística. No início do século $\mathrm{XX}$, com Saussure e Bloomfield, havia uma lingüistica descritiva, utilizando "o método indutivo em larga escala". Já o método empregado na GGT, é "bipotéticodedutivo e seu modelo emprega técnicas de item-e-processo, com um conjunto de regras, grande parte delas ordenadas" (p. 6).

Esses dois pontos de vista tanto sobre o objeto quanto sobre o método nos permitem compreender que objeto e método são representados

${ }^{6}$ Em todas as citações da obra em questão, os grifos são do autor.
7 Na tradução do Curso de Lingüística Geral, de Saussure, parole está traduzida como fala. 
conforme a abordagem ou filiação a que o sujeito está vinculado. Assim, o campo da Linguística está representado a partir do olhar que se lança sobre seu objeto, determinando, por sua vez, o método utilizado. É nesse sentido, portanto, que se concebe o que seria a Linguística na conjuntura em questão, uma vez que, como bem destaca o livro introdutório de Scliar Cabral, "De uma noção bem clara sobre o objeto da linguística depende a compreensão do que seja esta ciência" (p. 7).

Tendo em vista essa abordagem em torno do objeto e do método, enfatizamos o capítulo que segue: Divisões da Linguística, cuja divisão é determinada pelo modo como se compreende seu objeto. Primeiramente, verifica-se um esquema do capítulo, enfatizando que as divisões da Linguística podem apresentar dois eixos: A Linguística Teórica ou a Linguística Aplicada. Porém, esta última é subordinada à teórica, na concepção de Scliar Cabral.

Diante disso, podemos dizer que a especificidade desse livro introdutório está no fato de priorizar a questão do objeto da Linguística, o qual é central para as várias perspectivas dos estudos linguísticos, embora cada uma o enfatize de um modo em específico. Para nós, diante do viés em que nos situamos, isso nos leva a compreender que toda filiação teórica, o modo como se representa o objeto da Linguística é perpassado por uma questão ideológica e histórica. Para Orlandi (2002, p. 156), "quando os autores se filiam a uma teoria e não outra, e quando fazem um recorte do objeto de conhecimento, estão produzindo uma política de ciência com conseqüências para uma política social”. Considerando o recorte que está em circulação no Introdução à lingüística, de Scliar Cabral, nos anos de 1960/1970, quando a Linguística está se consolidando em todo território brasileiro, entendemos que a divulgação desses saberes irão influenciar o desenvolvimento dos estudos linguísticos no sul, trazendo contribuições para as questões que dizem respeito à relação entre a Linguística Teórica e Linguística Aplicada.

Há, pois, nessa conjuntura, a circulação de um discurso sobre a Linguística a partir da atualização, na dimensão da formulação discursiva, do discurso de autores e textos bases que configuraram esse domínio no início e metade do séc. XX. Ao fazer circular um discurso sobre, consideramos que há um gesto de interpretação sobre o que representa a Linguística nesse momento sócio-histórico. Todo recorte sobre dado campo de saber resulta da estrita relação entre a produção discursiva e a exterioridade, sendo a determinação histórica e ideológica que configuram a constituição do discurso, bem como a posição do sujeito que aí se instala. Assim, entendemos que nessa conjuntura visa-se a divulgar a Linguística pela ênfase em seu objeto e método por serem essenciais para consolidar esse domínio de saber, além de contribuir para o desenvolvimento dos estudos futuros.

Destacando o livro Introdução à Linguística - I. Objetos teóricos, organizado por José Luiz Fiorin, observamos que há uma organização distinta 
no modo como os saberes da Linguística estão apresentados, uma vez que não há o estabelecimento de uma divisão dos estudos que integram o domínio da Linguística, o que se verifica, pelo sumário, são diferentes reflexões sobre questões linguísticas que perpassam o momento atual dos estudos linguísticos.

No prefácio, verificamos como o livro foi organizado, o qual é destinado, sobretudo, aos alunos do curso de Letras, ressaltando que um dos pontos que envolve a proposta curricular desse curso são os fatos linguísticos a partir da Linguística. O autor destaca que "um currículo é a seleção de uma série de conteúdos com vistas a alcançar determinados objetivos" (FIORIN, 2005 , p. 8), ou seja, vincula-se a uma questão institucional, ocorrendo o mesmo para a composição de um livro introdutório, uma vez que é necessário selecionar o que vai integrá-lo, não é possível abarcar o todo. Assim, o recorte que se propõe nesse livro busca ir "além do senso comum na observação dos fenômenos linguísticos" para tornar possível "uma posição investigativa diante da linguagem humana" (Ibid., p. 8).

Por se tratar de um livro introdutório, é importante considerar "que alguns conceitos foram selecionados e não outros e, ao mesmo tempo, eles não foram tratados em toda a sua complexidade" (Ibid., p. 8). Diante dessas questões, o objetivo do Introdução à Linguística I é promover ao aluno "uma visão de conjunto dos modos como a ciência da linguagem trata do fenômeno linguístico" (Ibid., p. 8). O objetivo é determinante para as escolhas ou recortes diante do domínio da Linguística que serão postos em circulação pelo livro introdutório.

Considerando o sumário, não há uma preocupação, como no livro anterior, em apresentar o que é a Linguística, visto que é um domínio já consolidado, como podemos observar pelo título do seguinte texto que compõe o livro: "A língua como objeto da Linguística". Ou seja, desloca a questão de definir o que é a Linguística para tratar de seu objeto em si. Também não se verifica um enfoque nas divisões da Linguística, o que se tem são reflexões acerca dos fenômenos linguísticos calcadas a uma perspectiva teórica em específico.

A Linguística é entendida como uma ciência que abarca diferentes modos de conceber o fenômeno linguístico. Isto é, pensar esse campo de estudo, nos dias de hoje, é considerar as várias vertentes que integram os estudos linguísticos, pois o interesse não é marcar ou consolidar esse domínio, mas divulgar e fazer circular as diversas possibilidades de se estudar os fenômenos linguísticos.

Entendemos que o enfoque dado à Linguística não se vincula a uma questão que se fecha nas disciplinas ligadas a esse domínio, porém, é necessário observar que as escolhas das questões a serem tratadas marcam uma posição ideológica e histórica diante do que se considera como pertinente circular e divulgar. Essa abordagem não é observada no volume II, que trata 
dos 'Princípios de análise', pois volta uma questão disciplinar em sua organização, apresentando uma visão sobre as diversas disciplinas que integram a Linguística, como: Fonética; Fonologia; Morfologia; Sintaxe; Semântica; Pragmática; Discurso.

A estrutura que observamos no volume II permite-nos refletir sobre o que Foucault ressalta a respeito da disciplina. Para o autor, a disciplina vincula-se a "um princípio de controle da produção do discurso. Ela lhe fixa os limites pelo jogo de uma identidade que tem a forma de uma reatualização permanente das regras" (2007, p. 36). Nesse sentido, o que envolve uma disciplina relaciona-se também a uma questão de recorte em razão de que ela "não é a soma de tudo o que pode ser dito de verdadeiro sobre alguma coisa, não é nem mesmo o conjunto de tudo o que pode ser aceito, a propósito de um mesmo dado, em virtude de um princípio de coerência ou de sistematicidade" (Ibid., p. 31).

Nesse sentido, essa materialidade permite-nos compreender como a Linguística é entendida na conjuntura sócio-histórica e ideológica que envolve os anos 2000, permitindo-nos dizer que sua concepção não se restringe a um olhar que se volta para sua constituição como ciência, mas para as diferentes abordagens que a integram decorrentes do seu desenvolvimento no âmbito brasileiro.

\section{Considerações finais}

Nos livros introdutórios selecionados, observamos que há diferenças no modo como representam o domínio da Linguística, pois, para cada conjuntura, há uma representação distinta do 'sistema de objetos' (cf. AUROUX, 2008). Isso nos aponta para a relação que o saber tem com o tempo e a exterioridade. Conforme Auroux (Ibid.), o saber não é estático, ele se vincula a algo anterior e se projeta para um futuro, ou seja, o saber é contínuo e relaciona-se com as condições sócio-históricas e ideológicas.

Nesse sentido, o olhar que se tem sobre o que é a Linguística em cada livro introdutório está vinculado às condições de produção e ao objetivo que se tem com determinada circulação e divulgação. Diante das condições que envolvem a produção discursiva do Introdução à lingüística, de Scliar Cabral, observamos que o interesse nessa conjuntura é consolidar tanto a Linguística quanto os sujeitos denominados linguistas. No entanto, ao observarmos como a Linguística repercute nos dias atuais, ou seja, em outra conjuntura sócio-histórica, entendemos que há outras condições que perpassam a produção discursiva, como vimos no livro Introdução à Linguística I e II, organizados por Fiorin, visando, sobretudo, à divulgação, através de sujeitos com formação em Linguística, dos diversos pontos de vistas desse fazer científico. 


\section{Referências}

ALTMAN, Cristina. A pesquisa lingüística no Brasil (1968-1988). 2. ed. São Paulo: Humanitas, 2004.

AUROUX, Sylvain. A questão da origem das línguas, seguido de A historicidade das ciências. Traduzido por Mariângela Pecciolli Gali Joanilho. Campinas, SP: RG, 2008.

FIORIN, José Luiz (org.). Introdução à Linguística. V. I. Objetos teóricos. 4. ed. São Paulo: Contexto, 2005.

(org.). Introdução à Linguística. V. II. Princípios de análise. 6. ed. São Paulo: Contexto, 2011.

FOUCAULT, Michel. A ordem do discurso. 15. ed. São Paulo: Loyola, 2007. ORLANDI, Eni. Terra à vista! Campinas, SP: Editora da Unicamp, 1990.

. Língua e conhecimento lingüístico: para uma história das idéias no Brasil. São Paulo: Cortez, 2002.

. Interpretação: autoria, leitura e efeitos do trabalho simbólico. 4. ed. Campinas, SP: Pontes, 2004.

PÊCHEUX, Michel. Sobre a (Des-)construção das Teorias Lingüísticas. Línguas e Instrumentos Lingüísticos, n. 2, 1999.

SCHERER, Amanda. Lingüística no sul: estudos das idéias e organização da memória. In: GUIMARÃES, Eduardo; BRUM DE PAULA, Miriam. (orgs.). Sentido e memória. Campinas, SP: Pontes, 2005.

SCLIAR CABRAL, Leonor. Introdução à Lingüística. 7. ed. Rio de Janeiro: Globo, 1988.

XAVIER, Rosemary Candaten. Leonor Scliar Cabral: uma historicidade possível na produção do saber sobre a lingüística na mídia impressa do RS. 2004. 108f. Dissertação (Mestrado em Letras). Programa de Pós-Graduação em Letras, Universidade Federal de Santa Maria. Santa Maria, RS: UFSM, 2004. 